\title{
HOW DID I FEEL BEFORE BECOMING DIABETES RESILIENCE? A QUALITATIVE STUDY IN ADULT TYPE 2 DIABETES MELLITUS
}

\author{
Hidayat Arifin $^{1}$, Kusnanto ${ }^{2 *}$, Ika Yuni Widyawati ${ }^{3}$ \\ ${ }^{1,2,3}$ Faculty of Nursing, Universitas Airlangga \\ Email*: kusnanto@fkp.unair.ac.id
}

\begin{abstract}
Introduction: Diabetes resilience is a condition where people with diabetes can accept their incurable disease as well. It is characterized by regular blood sugar, a diet-controlled, active, and not stressful. However, various kinds offeelings must be passed to become diabetes resilience. The study aimed to know what adult type 2 diabetes mellitus (T2DM) felt before becoming resilient. Methods: A qualitative phenomenology design was conducted to observe the experience of adult T2DM before becoming resilient. The total participants were ten T2DM patients obtained through snowball sampling. The data collection was conducted through in-depth interviews with interview guidelines and analyzed using qualitative thematic analysis. Results: The results of the study found two major themes namely psychological response and diet. Participants felt quite severe stress when diagnosed with diabetes mellitus and felt difficulty when undergoing diabetes mellitus treatment. In addition, changes in diet are also felt very difficult by participants in undergoing a diabetes mellitus diet. Conclusions: Psychological responses and diet are the hard parts felt by the participants. Increasing understanding, support, and acceptance can be one strategy to increase diabetes resilience in participants.
\end{abstract}

Keywords: diabetes mellitus; diet; psychologic responses; resilience.

\section{INTRODUCTION}

Diabetes mellitus (DM) is a chronic disease with an increasing number of morbidity every year (WHO, 2018). In addition, other chronic illnesses caused by type 2 diabetes mellitus (T2DM) also increase mortality in Indonesia (National Institute of Health Research and Development Indonesia, 2018). Management of DM regiment therapy, which includes regulation of blood sugar through diet, medication, and stress management, becomes very difficult for DM sufferers to undergo (Sukartini et al., 2020). That is because DM patients who have not been resilient. Many obstacles must be faced by DM to achieve resilient conditions. In addition, patients with T2DM are very susceptible to distress due to the continuous treatment and diet that must be followed (Swoboda et al., 2017). Complications related to T2DM are a significant cause of morbidity and mortality and have a severe impact on patients' quality of life (Hsieh, Lee et al, 2016).

The prevalence of DM patients every year always increases. The International Diabetes Federation (IDF) states that the prevalence of T2DM in the world is $1.9 \%$ and has made T2DM as the seventh leading cause of death in the world. The incidence of T2DM is expected to increase again by $165 \%$ in the year (ADA, 2014). The number of diabetics in Indonesia is 8.5 million, placing Indonesia 7 th out of 10 countries with the highest number of people with diabetes. It is estimated that in 2035 the global prevalence of T2DM will increase to nearly 600 million (Shearman \& Rawashdeh, 2016). The data from the Baseline Health Research of Indonesia showed that T2DM patients aged $\geq 15$ years in 2013 had an incident rate of $6.9 \%$. This increased in 2018 to become $8.5 \%$. The prevalence was higher in women at $12.7 \%$ than in men at $9 \%$. The T2DM patients who did not take medicine made up $11 \%$ (National Institute of Health Research and Development Indonesia, 2018).

Resilience defined as the development, ability, or outcome of successful adaptation in spite of challenging or threatening conditions (Masten, 2001). Victor and Stronge have been elaborating on this definition by distinguishing the role of individual characteristics such as one's resources, weaknesses, and abilities from the importance of the goodness-of-fit between the individual and the environment (ReedVictor \& Stronge, 2002). T2DM Patients with 
resilience disorder will be caused negative adaptation on treatment (Kim et al., 2019). This can lead to a decrease in the ability to take care of themselves, such as the ability to seek treatment, activity, and diet (Alhaik et al., 2019; Wilson et al., 2017). Based on the explanation above, the experience felt by DM participants before reaching resilience needs further research. This can be used as a basis for determining interventions to improve resilient conditions in people with DM. Thus, the study aimed to find out what is experienced by people with DM before achieving resilient requirements through a qualitative approach.

\section{METHODS}

A qualitative phenomenology design was chosen to find out what is experienced by people with DM before achieving diabetes resilience. A phenomenological approach that aims to study, develop, explore or discover knowledge by using a scientific approach in giving meaning or interpreting a number of things that are meaningful to humans (Creswell \& Creswell, 2018). The findings from qualitative research are based on the real-life experiences of people who are directly involved in a phenomenon (Polit, D.F \& Beck, 2013). Phenomenology focuses on the experience of human life and is an approach to gain insight into what people's life experiences are and what they mean (Polit, D.F \& Beck, 2013). The following steps are a part of phenomenology in order to ensure the best possible outcome: 1) turning to the nature of the lived experience, 2) exploring the experience as we live it, 3) reflecting on essential themes, 4) describing the phenomenon through the art of writing and rewriting 5) maintaining a strong relation to the phenomenon, and 6) balancing the research context by considering parts and whole (Van Manen, 1997).

The participants of this study were ten T2DM patients obtained through the snowball sampling technique. Method of the approach used face to face. The inclusion criteria were: 1) Participants with diagnostic of type 2 diabetes mellitus data from public health center; 2) The participant with long-suffering from T2DM for minimal five years; 3) Participants aged 24 - 64 years (adults); 4) Participants can communicate with Bahasa or Javanese language; 5) Participants with regulated blood plasma glucose (>200 mg/dL); 6) participant with resilience condition (controlled blood sugar, good diet management, medicine, and activity). The participants who fit the inclusion criteria, researchers, were assisted by the person in charge of the chronic disease program at the public health center. During the research, no participants dropped out.

The study was conducted in four Public Health Centers in Surabaya, East Java Province, Indonesia, for two months, November - December 2019. The participants determined the location of the interview at the time of the informed consent contract. During the data collection process, only conducted by researchers and participants and not accompanied by family or other people.

The researchers themselves are the data collection tools, and thus they cannot be represented or delegated. The data collection tools consisted of audio recorders, field notes made during the interview process, and interview guidelines conducted by authors. The interview questions included what people with T2DM experience before becoming resilient. Questions refer to guidelines that have been created by the author. Questions begin with open questions such as "how," "can you explained," etc. The duration of the interview is approximately 30 minutes. Data is said to be saturated if more than half of the total participants answer with the same keywords. The interview process was carried out during three meetings. The first meeting for introductions to participants, the second meeting to conduct the interview process, and the third meeting to conduct interviews again for questions that have not been answered by participants. After finishing verbatim and analysis, the researcher contacted the 
participants again to ascertain whether the results of the interview were appropriate or not.

The interview data were analyzed using qualitative thematic analysis by searching for any themes that emerge. The analysis process is assisted with NVIVO 12 software. This becomes important when looking into the description of a phenomenon or case. The stages of thematic analysis include: 1) developing manual code, 2) conducting reliability tests on the code, 3 ) summarizing the data and identifying the initial themes, 4) applying templates to the codes and supplementary codes, 5) linking the codes and identifying themes, and 6) strengthening and validating the theme (Fereday \& MuirCochrane, 2006).

This study was registered to the research ethics board of the Health Research
Ethics Commission of the Faculty of Nursing, Universitas Airlangga, No.1779-KEPK, published on October 3, 2019.

\section{RESULTS}

Out of ten participants, the age range of participants was at the age of 39 - 55 years. More than half of the total participants were married women. Participant characteristic data also shows that there are participants with divorced life and death status. Most respondents work as housewives and the education high school. Participants experience diabetes mellitus in the range of 5-8 years. Most participants with regular fasting blood sugar $<126 \mathrm{mg} / \mathrm{dL}$ (Table 1).

Table 1. Participant Characteristics $(\mathrm{n}=10)$

\begin{tabular}{|c|c|c|c|c|c|c|c|}
\hline Code & Age & Gender & $\begin{array}{l}\text { Marital } \\
\text { Status }\end{array}$ & Job & Education & $\begin{array}{l}\text { Length } \\
\text { of Sick } \\
\text { (year) }\end{array}$ & $\begin{array}{l}\text { Glycemic } \\
\text { control } \\
(\mathrm{mg} / \mathrm{dL})\end{array}$ \\
\hline $\mathrm{P} 1$ & 43 & $\mathrm{~F}$ & Married & Housewife & High School & 7 & 127 \\
\hline $\mathrm{P} 2$ & 55 & $\mathrm{~F}$ & Married & Housewife & High School & 6 & 112 \\
\hline P3 & 50 & M & Married & Not Work & High School & 8 & 122 \\
\hline $\mathrm{P} 4$ & 40 & $\mathrm{~F}$ & Married & Housewife & High School & 6 & 125 \\
\hline P5 & 45 & M & Married & $\begin{array}{l}\text { Groceries } \\
\text { Seller }\end{array}$ & High School & 7 & 120 \\
\hline P6 & 47 & $\mathrm{~F}$ & Married & Housewife & DIII & 6 & 120 \\
\hline P7 & 43 & M & Married & Banker & Bachelor & 5 & 120 \\
\hline P8 & 39 & $\mathrm{~F}$ & Widow & $\begin{array}{l}\text { Groceries } \\
\text { Seller }\end{array}$ & High School & 6 & 125 \\
\hline P9 & 45 & $\mathrm{~F}$ & Married & Teacher & Bachelor & 6 & 130 \\
\hline P10 & 46 & M & Widower & $\begin{array}{l}\text { Government } \\
\text { Officer }\end{array}$ & DIII & 7 & 115 \\
\hline
\end{tabular}

P: Participants; F: Female; M: Male; mg/dL: milligrams per deciliter; DIII: Diploma

The results of the study, there were two themes, namely psychological response, and diet. The psychological response consists of two sub-themes, namely grieving and attitude.
In addition, the diet theme consists of two subthemes, namely dietary habits and diet perception (Table 2). 
Table 2. Theme Distribution

\begin{tabular}{ll}
\hline Themes & Sub-themes \\
\hline Psychologic Response & Grieving \\
& Attitude \\
\hline Diet & Dietary habit \\
& Diet perception \\
\hline
\end{tabular}

\section{Theme 1: Psychologic response}

Psychological responses felt by participants before becoming resilient, namely grieving and changing attitudes. The grieving response shown by the participants included denying the diagnosis of diabetes mellitus (Quotes 1-2). Participants were also angry with their condition (Quotes 4-5). Participants felt depressed with the situation (Quotes 6-8) until, in the end, participants can accept the condition of diabetes mellitus well (Quotes 9-10). In addition, the action taken by the participants to become resilient is to fight for routine treatment and control (Quote 11-13). Besides that, participants have the initiative to recover and take care (Quotes 14-15), as well as divert the thoughts of stress and fear experienced by

Table 3. Summary of Participant Statements

\begin{tabular}{|c|c|}
\hline Quotes & tatements \\
\hline 1. & "I don't believe how come I can get this diabetes ..." (P9) \\
\hline 2. & "I always thought and could not believe I was suffering from diabetes mellitu \\
\hline 3. & "I was emotional. I was easily emotional at that time ..." (P9). \\
\hline 4. & "I was angry that my wishes were not followed at that time ..." (P7) \\
\hline 5. & "once the time I refused mas with my sick condition, I could not ..." (P8). \\
\hline 6. & $\begin{array}{l}\text { "When I remember this, I am always sad, I always think of this pain. What about the } \\
\text { children if I am sick and not recovered ..." (P1). }\end{array}$ \\
\hline 7. & "at first, I was unfortunate when I found out that I had diabetes mellitus" (P6). \\
\hline 8. & $\begin{array}{l}\text { "I was terrified, I was afraid that this pain could not be healed, and I died like my parents } \\
\ldots \text {... (P10). }\end{array}$ \\
\hline 9. & "now, I have accepted this pain. I live it with sincerity.." (P8). \\
\hline 10. & $\begin{array}{l}\text { "The important thing is not stress. Live happily. Alhamdulillah, now I can accept this pain" } \\
\text { (P4). }\end{array}$ \\
\hline 11. & $\begin{array}{l}\text { "It must be routine to take medicine, not be late. If the medicine runs out, go to the } \\
\text { pharmacy or to the health center" }(\mathrm{P} 2) \text {. }\end{array}$ \\
\hline 12. & $\begin{array}{l}\text { "must be spirited, must not be weak. I must be strong and healthy. I am sure I can be } \\
\text { healthy and heal" (P3). }\end{array}$ \\
\hline 13. & "if I'm passionate and healthy, I can do anything ..." (P5). \\
\hline 14. & "In essence, everything starts with me. I can definitely be healthy ..." (P1). \\
\hline 15. & "as much as possible, I look for other activities, so I am not bored to do self-care..." (P8). \\
\hline 16. & $\begin{array}{l}\text { "must not be stressed and afraid, must be sure and be healthy. All I live with pleasure" } \\
\text { (P4). }\end{array}$ \\
\hline 17. & "In the past, I ate disorganized things, liked careless food, and liked to eat at night" (P7) \\
\hline 18. & et food" (P1) \\
\hline 19. & "I'm bored if I have to take medicine and eat the same menu" (P3). \\
\hline 20. & "I struggled while on this diet. It was difficult to change my previous habits" (P4). \\
\hline 21. & "blood sugar will be raised again if I do not comply with the diet ..." (P6). \\
\hline
\end{tabular}


participants with diabetes mellitus (Quote 16) (See the quotes on table 3 ).

\section{Theme 2: Diet}

Participants in the process of resilience have difficulty in managing a diet in diabetes mellitus. This can be seen from the participant's irregular dietary behavior and still likes to eat sweet foods (Quote 17-18). In addition, dietary perceptions that must be undertaken by participants make participants bored with their diet menu (Quote 19). Participants also found it challenging to go on a diet and adjust to their current conditions (Quote 20). When participants learned the importance of diets for diabetes mellitus, participants felt afraid that if they did not comply with their diets, their blood sugar would increase (Quote 21) (See the quotes on table 3 ).

\section{DISCUSSIONS}

The results showed that participants felt sad about their condition when diagnosed with diabetes mellitus. In addition, participants also experienced prolonged depression. Participants refused with the condition and did not believe that he was suffering from diabetes mellitus. In the participant's perception, that diabetes mellitus could not be cured and could cause complications (Chittem et al., 2019). The excessive worry from participants is a symptom of stress (Madhu et al., 2019; Rariden, 2019). The lack of knowledge of partisans can cause this. Demographic data shows that the majority of participants have senior high school education. Increasing knowledge about diabetes mellitus care becomes very important (Shahla et al., 2017). So that participants can do diabetes management properly.

Participants who experience the reword of diabetes mellitus will be very range to experience psychological disorders and mental health. This can cause the participant to experience depression, anxiety, and disruption in diet control (Team, 2020). Participants who experience psychological disorders can create self-care that can not be done with a maximum like drug management, diet, stress, and activity
(Kalra et al., 2018). Participants with unstable emotions make blood sugar levels uncontrolled, which can have an impact on self-management and the ability to control diabetes mellitus. Participants who are depressed tend to be unable to perform activities or sports to the fullest (Diabetes Australia - National diabetes services scheme, 2016). In addition, participants were unable to manage their diets well (Siopis et al., 2020). Participants' sleep patterns can also be disturbed, which can have a severe impact on the overall quality of life (Azharuddin et al., 2020).

The results also showed that participants experienced difficulties in managing their diets. Participants revealed that the change in the adaptation from behavior that used to consume drinks and sweet foods and had to change was a challenging condition. Changes to adaptation become difficult for participants and must be done slowly and gradually (Goldfarb-Rumyantzev et al., 2012). Participants said they were bored and had difficulty in dieting. Dietary management for people with diabetes is difficult to implement. That is because participants need time to be able to accept their conditions (Siopis et al., 2020)(Stojek et al., 2019).

Increased good knowledge and the role of health workers can reduce psychological disorders and dietary disorders experienced by participants (Shahla et al., 2017). Participants revealed that with the support of immediate family or health workers can provide encouragement and provide a sense of attention (Litchman et al., 2018; Saidi et al., 2019). Improved self-management can also give participants the ability to properly manage diabetes mellitus (Pamungkas \& Chamroonsawasdi, 2020). This can be seen from the results of research that show that participants can struggle in self-care, have strong initiative and enthusiasm to achieve healthy conditions and regular blood sugar. In addition, participants also adhere to the diet to maintain normal blood sugar levels. In this case, the support of the closest people and the attention of health workers can improve the 
ability of participants to undergo diabetes mellitus management properly (Levy et al., 2017). Thus, participants can become resilient through the stages of determination, endurance, adaptability, and recoverability (Taormina, 2015).

The limitations of this study only explored the experience of T2DM patients before becoming resilient. This study will be better by doing exploration to reach the stage of resilience so that it can be an example for T2DM patients with unregulated blood sugar. However, this study explores the experience of T2DM patients before becoming resilient. This can be a picture for participants to know the experience, so participants do not need to worry too much. It is hope, participants can do positive things that can improve the ability to manage diabetes properly.

\section{CONCLUSIONS}

Psychological responses and diets experienced by participants are the initial conditions felt by participants when diagnosed with diabetes mellitus. Participants experience denial with the condition so that finally, participants can accept the condition well. Support from family and the environment, such as health workers, can provide more enthusiasm and attention for participants to undergo diabetes mellitus treatment.

\section{ACKNOWLEDGMENT}

The researcher would like to thank the head of the Public Health Center in Surabaya, Indonesia, for permitting to conduct the study and for the participants who were cooperative and willing to carry out the research process.

\section{FUNDING}

This research received funding assistance from the Ministry of Research and Technology / National Agency for Research and Innovation, Indonesia, in the Master's Thesis Program category.

\section{REFERENCES}

ADA, (American Diabetes Associatin). (2014). Standards of Medical Care in Diabetes 2014. Diabetes Care2, 37(1), S14.

Alhaik, S., Anshasi, H. A., Alkhawaldeh, J., Soh, K. L., \& Naji, A. M. (2019). An assessment of self-care knowledge among patients with diabetes mellitus. Diabetes and Metabolic Syndrome: Clinical Research and Reviews, 13(1), 390-394. https://doi.org/10.1016/j.dsx.2018.10.010

Azharuddin, M., Kapur, P., Adil, M., Ghosh, P., $\&$ Sharma, M. (2020). The impact of sleep duration and sleep quality on glycaemic control in Asian population with type 2 diabetes mellitus: A systematic literature review and meta-analysis of observational studies. Clinical Epidemiology and Global Health, March, 1-9. https://doi.org/10.1016/j.cegh.2020.03.00 6

Chittem, M., Chawak, S., Sridharan, S. G., \& Sahay, R. (2019). The relationship between diabetes-related emotional distress and illness perceptions among Indian patients with Type II diabetes. Diabetes and Metabolic Syndrome: Clinical Research and Reviews, 13(2), 965-967.

https://doi.org/10.1016/j.dsx.2018.12.018

Creswell, J. W., \& Creswell, J. D. (2018). Research Design: Qualitative, Quantitative, and Mixed Methods Approaches. In Journal of Chemical Information and Modeling (5th ed., Vol. 53, Issue 9). Sage Publications, Incorporated.

https://doi.org/10.1017/CBO9781107415 324.004

Diabetes Australia - National diabetes services scheme. (2016). Diabetes and emotional health. 02, 9, 31-49, 113-133.

Fereday, J., \& Muir-Cochrane, E. (2006). Demonstrating Rigor Using Thematic Analysis: A Hybrid Approach of Inductive and Deductive Coding and Theme Development. International Journal of Qualitative Methods, 5(1), 8092. 
How Did I Feel Before Becoming Diabetes Resilience? ... (Hidayat, et.al)

https://doi.org/10.1177/16094069060050 0107

Goldfarb-Rumyantzev, A. S., Rout, P., Sandhu, G. S., Barenbaum, A., Patibandla, B. K., Narra, A., Chawla, V., \& Williams, M. (2012). Social adaptability index predicts overall mortality in patients with diabetes. Journal of Diabetes and Its Complications, 26(1), 44-49. https://doi.org/https://doi.org/10.1016/j.jd iacomp.2011.12.002

Hsieh, Y. L., Lee, F. H., Chen, C. L., Chang, M. F., \& Han, P. H. (2016). Factors Influencing Intention to Receive Examination of Diabetes Complications. Asian Nursing Research, 10(4), 289-294. https://doi.org/10.1016/j.anr.2016.10.004

Indonesia, I. N. I. of H. R. and D. (2018). Main Resulth of Baseline Health Research 2018. Ministry of Health of the Republic of Indonesia.

Kalra, S., Jena, B. N., \& Yeravdekar, R. (2018). Emotional and psychological needs of people with diabetes. In Indian Journal of Endocrinology and Metabolism (Vol. 22, Issue 5, pp. 696-704). Wolters Kluwer Medknow Publications. https://doi.org/10.4103/ijem.IJEM_579_1 7

Kim, G. M., Lim, J. Y., Kim, E. J., \& Park, S. M. (2019). Resilience of patients with chronic diseases: A systematic review. Health and Social Care in the Community, 27(4), 797-807. https://doi.org/10.1111/hsc.12620

Levy, M., Burns, R. J., Deschênes, S. S., \& Schmitz, N. (2017). Does Social Support Moderate the Association Among Major Depression, Generalized Anxiety Disorder, and Functional Disability in Adults With Diabetes? Psychosomatics, 58(4), 364-374. https://doi.org/https://doi.org/10.1016/j.p sym.2017.03.004

Litchman, M. L., Rothwell, E., \& Edelman, L. S. (2018). The diabetes online community: Older adults supporting selfcare through peer health. Patient
Education and Counseling, 101(3), 518523.

https://doi.org/https://doi.org/10.1016/j.p ec.2017.08.023

Madhu, S. V, Siddiqui, A., Desai, N. G., Sharma, S. B., \& Bansal, A. K. (2019). Chronic stress, sense of coherence and risk of type 2 diabetes mellitus. Diabetes \& Metabolic Syndrome: Clinical Research \& Reviews, 13(1), 18-23. https://doi.org/https://doi.org/10.1016/j.d sx.2018.08.004

Masten, A. S. (2001). Ordinary magic: Resilience processes in development. American Psychologist, 56(3), 227-238. https://doi.org/10.1037/0003066X.56.3.227

Pamungkas, R. A., \& Chamroonsawasdi, K. (2020). Self-management based coaching program to improve diabetes mellitus self-management practice and metabolic markers among uncontrolled type 2 diabetes mellitus in Indonesia: A quasiexperimental study. Diabetes \& Metabolic Syndrome: Clinical Research \& Reviews, 14(1), 53-61. https://doi.org/https://doi.org/10.1016/j.d sx.2019.12.002

Polit, D.F \& Beck, C. T. (2013). Nursing Research; Appraising Evidence for Nursing Practice (7th ed.). Lippincott William \& Wilkins.

Rariden, C. (2019). Diabetes Distress: Assessment and Management of the Emotional Aspect of Diabetes Mellitus. The Journal for Nurse Practitioners, 15(9), 653-656. https://doi.org/https://doi.org/10.1016/j.n urpra.2019.06.020

Reed-Victor, E., \& Stronge, J. H. (2002). Homeless students and resilience: Staff perspectives on individual and environmental factors. Journal of Children and Poverty, 8(2), 159-173. https://doi.org/10.1080/10796120220000 05375

Saidi, S., Milnes, L. J., \& Griffiths, J. (2019). Are we doing it right? Self-care support 
for patients with type 2 diabetes in urban areas in Malaysia. Enfermería Clínica, 29, 691-697.

https://doi.org/https://doi.org/10.1016/j.e nfcli.2019.04.106

Shahla, L., Vasudev, R., Chitturi, C., Rodriguez, C., \& Paul, N. (2017). Diabetes mellitus treatment-Related medical knowledge among health care providers. Diabetes and Metabolic Syndrome: Clinical Research and Reviews, 11(1), 69-72. https://doi.org/10.1016/j.dsx.2016.08.010

Shearman, C. P., \& Rawashdeh, M. (2016). Foot complications in patients with diabetes. Surgery (Oxford), 34(4), 192197.

https://doi.org/10.1016/j.mpsur.2010.02. 002

Siopis, G., Colagiuri, S., \& Allman-Farinelli, M. (2020). Dietitians' experiences and perspectives regarding access to and delivery of dietetic services for people with type 2 diabetes mellitus. Heliyon, $6(2)$,

e03344 https://doi.org/https://doi.org/10.1016/j.h eliyon.2020.e03344

Stojek, M. M., Maples-Keller, J. L., Dixon, H. D., Umpierrez, G. E., Gillespie, C. F., \& Michopoulos, V. (2019). Associations of childhood trauma with food addiction and insulin resistance in African-American women with diabetes mellitus. Appetite, 141 , 104317 https://doi.org/https://doi.org/10.1016/j.a ppet.2019.104317

Sukartini, T., Theresia Dee, T. M., Probowati, R., \& Arifin, H. (2020). Behaviour model for diabetic ulcer prevention. Journal of Diabetes and Metabolic Disorders. https://doi.org/10.1007/s40200-01900484-1

Swoboda, C. M., Miller, C. K., \& Wills, C. E. (2017). Patient Education and Counseling Impact of a goal setting and decision support telephone coaching intervention on diet, psychosocial , and decision outcomes among people with type 2 diabetes. Patient Education and Counseling, 2016. https://doi.org/10.1016/j.pec.2017.02.007

Taormina, R. J. (2015). Adult Personal Resilience: A New Theory, New Measure, and Practical Implications. Psychological Thought, 8(1), 35-46. https://doi.org/10.5964/psyct.v8i1.126

Team, N. D. S. (2020). The Psychological Impact of Diabetes. Clinical Governance, 18, 1-4. https://www.drwf.org.uk/newsand-events/news/psychological-impactdiabetes

Van Manen, M. (1997). From meaning to method. Qualitative Health Research, 7(3), 345-369. https://www.scopus.com/inward/record.u ri?eid=2-s2.0-

0000281750\&partnerID $=40 \& \mathrm{md} 5=008 \mathrm{~b}$ ddb47d2b06e045817f86ee88d708

WHO. (2018). Diabetes. World Health Organization. https://www.who.int/newsroom/fact-sheets/detail/diabetes

Wilson, A. L., McNaughton, D., Meyer, S. B., \& Ward, P. R. (2017). Understanding the links between resilience and type-2 diabetes self-management: A qualitative study in South Australia. Archives of Public Health, 75(1), 1-13. https://doi.org/10.1186/s13690-0170222-8 